\title{
LONG-TERM OUTCOMES OF SYMPTOMATIC ELECTRODIAGNOSED CARPAL TUNNEL SYNDROME
}

\author{
Joao Aris Kouyoumdjian', Maria P.A. Morita², Amalia F.P. Molina', \\ Dirce M.T. Zanetta4 ${ }^{4}$ Adriana K. Sato ${ }^{3}$, Carlos E.D. Rocha ${ }^{6}$, Claudia C. Fasanella ${ }^{6}$
}

\begin{abstract}
This study was done to evaluate the long-term patient's satisfaction after carpal tunnel syndrome (CTS) electrodiagnostic done between 1989 and 1994 (5 to 10 years follow-up). Mail contact was made to 528 consecutive cases with a questionnaire to be filled; 165 patients responded after 19 exclusions. CTS severity was graded from 0 (incipient) to 4 (severe) after a combination of median sensory distal latency, sensory median-radial latency difference and amplitude of the median compound muscle action potential. Current symptoms ("cure", improved, unchanged or worsed) and the therapy utilized, either surgical or conservative, were analyzed to the initial CTS severity, age and duration of symptomatology. Surgical release was done in 114 cases (69\%). Patient's satisfaction after surgical and non-surgical were respectively, $77.6 \%$ and $16 \%$ ("cure"), $13.6 \%$ and $52 \%$ (much improved), $5.4 \%$ and $9.3 \%$ (little improved), $2.7 \%$ and $16 \%$ (unchanged), $0.7 \%$ and $6.7 \%$ (worsed). The frequency of "cure" versus unchanged/worsed or "cure"/much improved versus unchanged/worsed was highly significative (Fisher, P-value $<0.001$ ) and was not influenced by the CTS electrophysiological severity. There was no relationship between the outcome after surgery and duration of symptomatology, age or CTS severity. Conservative benefice was more prevalent in those with shorter symptomatology and older age; the majority of conservative failure cases had mild initial CTS. We concluded the excellent surgical benefice described by patients and the absence of any predictive factors based on CTS severity, age or duration of symptomatology for outcome.
\end{abstract}

KEY WORDS: carpal tunnel syndrome, median nerve, compression neuropathy, electrodiagnosis, nerve conduction.

\begin{abstract}
Síndrome do túnel do carpo: avaliação evolutiva de longo prazo após confirmação eletrodiagnóstica
RESUMO - 0 presente estudo tem por objetivo avaliar a terapia utilizada e o grau de satisfação dos pacientes que tiveram diagnóstico eletrofisiológico de síndrome do túnel do carpo (STC) entre 1989 e 1994 (528 casos); foram respondidas 184 cartas entre 528 enviadas (34,8\%) sendo utilizadas 165 . A gravidade do STC foi classificada de 0 a 4 de acordo com uma combinação de valores de latência distal sensitiva e amplitude do potencial de ação muscular composto do nervo mediano e diferença de latência sensitiva mediano/radial. As questões foram relativas a sintomatologia atual e terapêutica utilizada, cirúrgica ou conservadora. As respostas foram correlacionadas ao estudo de condução nervosa inicial, idade e tempo de sintomatologia. Os pacientes submetidos a cirurgia somaram $69 \%$ (114 casos). O benefício cirúrgico e não cirúrgico foi respectivamente de $77,6 \%$ e $16 \%$ ("cura"); $13,6 \%$ e $52 \%$ (melhora acentuada); $5,4 \%$ e 9,3\% (melhora leve); $2,7 \%$ e $16 \%$ (inalterado); $0,7 \%$ e $6,7 \%$ (piora). A freqüência de "cura" versus inalterado/pior ou "cura"/melhora acentuada versus igual/ pior foi significativa, maior no grupo cirúrgico (teste de Fisher, valor de $\mathrm{P}<0,001$ ), e não foi influenciada pelo padrão eletrofisiológico inicial. Não houve relação entre melhora ou piora após cirurgia e tempo de sintomatologia, idade ou gravidade eletrofisiológica iniciais. Os casos com melhora sem cirurgia tiveram menor tempo de sintomatologia e idade mais avançada. Os casos sem melhora após tratamento conservador apresentavam padrão eletrofisiológico leve em sua maioria. Conclui-se o excelente benefício cirúrgico para STC e a ausência de fatores preditivos definidos baseados na gravidade eletrofisiológica, idade e tempo de sintomatologia iniciais.
\end{abstract}

PALAVRAS-CHAVE: síndrome do túnel do carpo, nervo mediano, neuropatia compressiva, eletroneuromiografia, condução nervosa.

Electromyography Laboratory, Clinical Neurophysiology, Department of Neurological Sciences, State Medical School, São Jose do Rio Preto SP, Brazil: ${ }^{1}$ Associate-Professor (MD, PhD); ${ }^{2}$ Assistent-Professor (MD, MSc); ${ }^{3}$ Postgraduate student (MD, Department of Epidemiology and Social Medicine; ${ }^{4}$ Associate-Professor (MD, PhD); ${ }^{6}$ Resident (MD).

Received 16 July 2002, received in final form 10 October 2002. Accepted 30 October 2002.

Dr. João Aris Kouyoumdjian - Avenida Bady Bassitt 3896 - 15025-000 São José do Rio Preto SP - Brasil. FAX: 55172327757.

E-mail: jaris@terra.com.br 
Carpal tunnel syndrome (CTS) is the most common entrapment neuropathy in the upper limbs ${ }^{1,2}$. Prospective population-based studies have shown that the prevalence of electrophysiologically confirmed CTS in the Netherlands in 1985 was $5.8 \%$ in women and $0.6 \%$ in men $^{3}$; in another survey performed in southern Sweden in $1999^{4}$, the authors found a $2.7 \%$ prevalence of symptomatic subjects with clinically and electrophysiologically confirmed CTS.

Early diagnosis and treatment are important because delay can result in irreversible median nerve damage with persistent symptoms and permanent disability ${ }^{1}$.Non-surgical treatment includes: 1 . avoiding the activity precipitating the condition; 2 . splinting the wrist; 3 . local steroid injection; 4. short course of either oral steroids or nonsteroidal anti-inflammatory drugs; 5 . trial of diuretics especially when the symptoms are perimenstrual ${ }^{1}$. The surgical treatment of median nerve compression in carpal tunnel, first described in the 1940s (cited by Nancollas et al..$^{5}$ ) is one of the most common and widely accepted surgical procedure and the only approach that can offer the possibility of a definitive cure ${ }^{6,7}$. Electrodiagnosis is very sensitive and specific for the diagnosis and several studies have reported sensitivity in the range of 80 to $92 \%^{8}$ and most physicians rely on this method for clinical suspicion confirmation.

The present study was carried out in order to analyze through mail response, patient's satisfaction after 5 to 10 years follow-up of CTS electrodiagnosed.

\section{METHOD}

\section{Patients}

From September to November 1999, 528 letters were sent, corresponding to 1989-1994 consecutive CTS electrodiagnosed patients by reviewing a computer database of the Electromyography Laboratory (EMG Lab), State Medical School, Sao Jose do Rio Preto, Sao Paulo, Brazil. All patients had a clinically confirmed diagnosis of CTS, including hand paraesthesia, numbness, and pain mainly at night; isolated pain was not considered. All patients had bilateral nerve conduction studies (upper limbs, sensory and motor) including at least median and ulnar ones. Age, gender and duration of symptoms were obtained from the patient's notes in the EMG Lab.

\section{Electrophysiology (nerve conduction studies)}

All patients had bilateral nerve conduction studies using either ATI 9000 (ATI, São Paulo, Brasil) or Cantata (Dantec, Skovlunde, Denmark) eletromyography machine. Palmar temperatures were maintained above $31^{\circ} \mathrm{C}$ (digital thermometer, Braile Biomedica, Sao Jose do Rio Preto, SP, Brasil). Electrophysiological techniques are described as follows; sensory latencies were measured to the onset.
1- Median distal sensory latency (routine). The stimulation delivered on median nerve at wrist activate antidromic sensory action potentials at the second digit; we used a fixed $14 \mathrm{~cm}$ distance from the ring recording electrodes that were placed around the proximal (recording, cathode) and distal (reference, anode) interphalangeal joints. The absolute latency value was defined as abnormal when equal or greater than $3.0 \mathrm{~ms}(46.6 \mathrm{~m} / \mathrm{s})^{9}$. Prolongation of the distal sensory latency or absence of the sensory nerve action potential in CTS has been reported in 53\% to $98 \%$ of cases $^{7}$

2 - Median motor distal latency (MDL). Median nerve stimulation was delivered at wrist in order to activate the compound muscular action potential (CMAP) at the thenar eminence; we used a fixed $8 \mathrm{~cm}$ distance from the disc recording electrodes that were placed over the belly of the Abductor Pollicis Brevis (APB) muscle (recording, cathode) and just distal to the metacarpophalangeal joint (reference, anode). The absolute latency value was defined as abnormal when equal or greater than $4.25 \mathrm{~ms}^{9}$ and amplitude of the CMAP less than $4.0 \mathrm{mV}$. Prolonged MDL to the APB in other series of CTS vary from $29 \%$ to $81 \%{ }^{10}$. 3 - Sensory median-radial difference (MR). Median nerve stimulation was delivered at wrist in order to activate antidromic sensory action potentials at the thumb; we used an approximately $10 \mathrm{~cm}$ distance from the ring recording electrodes around the thumb. Radial nerve stimulation was delivered at the lateral edge of the radius in the distal forearm at the same line used for median nerve stimulation; the recording ring electrodes around the thumb were the same. The latency difference was defined as abnormal when equal or greater than $0.40 \mathrm{~ms}^{11}$. Prolongation of MR in CTS has been reported in $58 \%$ to $100 \%$ of cases $^{10}$. Percutaneous stimuli were delivered until supramaximal response obtained; pulse duration were $0.05 / 0.1 \mathrm{~ms}$ for sensory nerve stimulation and $0.2 / 0.5 \mathrm{~ms}$ for motor nerve stimulation; filters were set at $20 \mathrm{~Hz}$ and $2 \mathrm{kHz}$; the sweep speed was set at $1 \mathrm{~ms}$ per division; one-centimeter disc recording, either platinum or disposable electrodes, were used for motor and ring electrodes for sensory nerve studies; either disposable or Velcro around the forearm were used as ground.

An electrophysiological severity classification were done to order to form groups that could represent the same gradation and were based on median distal sensory latency (routine) and on the amplitude of the median CMAP. Group 0, routine and CMAP normal; MR abnormal Group 1, routine abnormal (equal or greater $3.0 \mathrm{~ms}$ ) and CMAP normal; Group 2, routine abnormal (equal or greater $3.0 \mathrm{~ms}$ ) and CMAP abnormal (equal or greater $1.0 \mathrm{mV}$ and less than $4.0 \mathrm{mV}$ ); Group 3, routine absent and CMAP abnormal (equal or greater $1.0 \mathrm{mV}$ and less than $4.0 \mathrm{mV}$ ); Group 4, routine absent and CMAP abnormal (absent or less than $1.0 \mathrm{mV}$ ). 


\section{Questionnaire}

A questionnaire was sent to each patient including a pre-paid returned envelope with the following questions: 1. How are the symptoms now (complete relief "cure", improved "much better", improved "little", unchanged, or worsed). 2. What kind of treatment was done (surgical or conservative, either by splinting the wrist, local steroid injection, use of drugs medicines or others). 3. Surgeon specialty. 4. Date and side of carpal release.

\section{RESULTS}

Of the 528 cases in the initial sample, 184 letters (34.8\%) were returned with a complete questionnaire done, $123(23.3 \%)$ were returned without response (address do not matched) and the remaining 221 (41.9\%) with no response at all; 89.4\% was female ( 472 cases) and $10.6 \%$ male ( 56 cases). A total of 19 patients were excluded after incorrect responses, death, carpal release before electrophysiological evaluation and evidence of polyneuropathy based on conduction abnormalities in nerves other than the median. The records of the remaining 165 patients, 158 female (95.8\%) and 7 male (4.2\%), were retained for final analysis and form the basis of this study. Surgery release was done in $114 / 165$ patients $(69.1 \%)$ corresponding to $147 / 222$ hands (66.2\%). Non-surgical procedures were done in 51/ 165 patients $(30.9 \%)$ corresponding to 75 hands (33.8\%). Correct medical specialty was obtained in 109 from 114 surgical cases corresponding to $48.7 \%$ orthopaedic surgery, $22 \%$ neurosurgery, $17.4 \%$ vascular surgery, $11 \%$ plastic surgery and $0.9 \%$ general surgery.

\section{General patient's satisfaction}

Patient satisfaction after surgery: complete relief "cure" in 114 hands (77.6\%), improved "much better" in 20 hands (13.6\%), improved "little" in 8 hands $(5.4 \%)$, unchanged in 4 hands $(2.7 \%)$ and worsed in 1 hand $(0.7 \%)$. The mean period between surgery and questionnaire response (follow-up) was 70 mon- ths for complete relief "cure" group and 72 months for unchanged/worsed group. Patient satisfaction after non-surgical procedures: complete relief "cure" in 12 hands (16\%), improved "much better" in 39 hands (52\%), improved "little" in 7 hands (9.3\%), unchanged in 12 hands (16\%) and worsed in 5 hands (6.7\%). A comparison between surgical and non-surgical cases in the complete relief "cure" group (114 versus 12 hands or $77.6 \%$ versus $16 \%$ ) and unchanged/worsed groups (5 versus 17 hands) revealed $\mathrm{P}<0.001$, Fisher-test.

\section{Age and patient's satisfaction}

The mean age of patients that underwent CTS released (surgical) in the complete relief "cure" group was 46 (24-70) years against 44 (39-58) years in the unchanged/worsed one. The mean age of patients that had non-surgical procedures in the complete relief "cure" group was 61 (48-79) years against 50 (30-83) years in the unchanged/worsed one.

\section{Duration of symptomatology \\ and patient's satisfaction}

The mean duration of symptomatology of patients that underwent CTS released (surgical) in the complete relief "cure" group was 43 (1-120) months against 50 (1-120) months in the unchanged/worsed one. The mean duration of symptomatology of patients that had non-surgical procedures in the complete relief "cure" group was 8 (1-48) months against 26 (1-120) months in the unchanged/worsed one.

\section{Nerve conduction studies severity}

and patient's satisfaction

The nerve conduction severity of patients that underwent CTS released (surgical) in the complete relief "cure" group (114 hands) was as follows: group 0 (7 hands, 6.1\%), group 1 (74 hands, 64.9\%), group 2 (17 hands, $14.9 \%$ ), group 3 (9 hands, $7.9 \%$ ) and

Table 1. Summary of the results of patient's satisfaction after surgical and non-surgical CTS treatment.

\begin{tabular}{|c|c|c|c|c|c|c|c|c|c|}
\hline \multirow[t]{2}{*}{ Procedure } & \multirow[t]{2}{*}{ Patient's satisfaction } & \multirow[t]{2}{*}{ Hands } & \multirow[t]{2}{*}{ Age * } & \multirow[t]{2}{*}{ Duration* } & \multicolumn{5}{|c|}{ Nerve Conduction Severity } \\
\hline & & & & & 0 & 1 & 2 & 3 & 4 \\
\hline & Complete relief "cure" & 114 & $46(24-70)$ & $43(1-120)$ & 7 & 74 & 17 & 9 & 7 \\
\hline \multicolumn{10}{|l|}{ Surgical } \\
\hline & Unchanged / Worsed & 5 & $44(39-58)$ & $50(1-120)$ & 1 & 2 & 2 & 0 & 0 \\
\hline & Complete relief "cure" & 12 & $61(48-79)$ & $8(1-48)$ & 0 & 8 & 3 & 0 & 1 \\
\hline \multicolumn{10}{|c|}{ Non-surgical } \\
\hline & Unchanged / Worsed & 17 & $50(30-83)$ & $26(1-120)$ & 0 & 12 & 4 & 1 & 0 \\
\hline
\end{tabular}

* Mean and range (years); ** Symptomatology, mean and range (months) 
group 4 (7 hands, 6.1\%). On the other hand, the nerve conduction severity in the unchanged/worsed group (5 hands) after surgery was as follows: group 0 (1 hand), group 1 (2 hands), group 2 (2 hands), groups 3 and 4 (no hands).

The nerve conduction severity of patients that had non-surgical procedures in the complete relief "cure" group (12 hands) was as follows: group 0 (no hands), group 1 (8 hands, 66.6\%), group 2 (3 hands, 25\%), group 3 (no hands) and group 4 (1 hand, 8.3\%). On the other hand, the nerve conduction severity in the unchanged/worsed group after non-surgical procedures (17 hands) was as follows: group 0 (no hands), group 1 (12 hands, 70.6\%), group 2 (4 hands, $23.5 \%$ ), group 3 (1 hand, $5.9 \%$ ) and 4 (no hands). The main findings are summarized on Table 1.

\section{DISCUSSION}

Our results clearly showed the great surgical benefice in CTS treatment based on long-term patient's satisfaction after confirmed electrodiagnosed cases when compared to non-surgical procedures, regardless surgery technique or surgeon specialty $(P$ $<0.001$, Fisher test, surgical versus non-surgical, complete relief "cure" versus unchanged/worsed). Non-surgical procedures either through medications or splints, avoiding activities precipitating the condition or many non-conventional referred ones like homeopathy, acupuncture or vitamins could not be measured ought to large variability on response or time of use. We could not find any relationship between the outcome after surgery and duration of symptomatology, age or CTS electrodiagnostic severity prior to surgery. Conservative benefice was more prevalent in those with shorter duration of symptomatology and older age. The majority of conservative failure cases had mild initial CTS, pointing out the confusing attempt to predict results and benefices.

We used a similar model as did Cseuz et al. ${ }^{12}$ in 1966 at Mayo Clinic. They described that the use of questionnaires to be answered and sent by mail for the interpretation of CTS recovery seemed admissible, since the manifestations of CTS are largely subjective and therefore best judged by the patient himself.

Our mean follow-up after CTS release was 71 months (5.9 years) comparable to the other series described by Cseuz et al. (3 years) ${ }^{12}$, DeStefano et al. ( 7.3 to 12 years $)^{13}$, Haupt et al. (5.5 years) ${ }^{14}$, Nancollas et al. (4.8 years) ${ }^{5}$ and Thurston and Lam (18 months) ${ }^{15}$. We found $91.2 \%$ complete relief "cure" and improved "much better" (good results) after surgery, comparable to other series as Haupt et al. $(86 \%)^{14}$, Cseuz et al. $(81 \%)^{12}$, Thurston and Lam
$(80 \%)^{15}$, Nancollas et al. $(87 \%)^{5}$, Harris et al. $(91.9 \%)^{16}$ and DeStefano et al. (nearly 6 times more likely to have symptoms resolution) ${ }^{13}$.

The duration of the symptoms had little bearing on the degree of recovery and those with poor results were clinically not different from those who had obtained good results from operation as also described by most series $s^{5,12,16,17}$. However, DeStefano et al. ${ }^{13}$ found that duration of CTS was one of the strongest factors influencing the effectiveness of CTS surgery; nearly all surgical patients who had successful outcomes had resolution of their symptoms by $6-12$ months after surgery.

Nerve conduction studies severity also failed as a factor determining prognosis and, even in severe cases, subjective recovery could be found, as also described in others series ${ }^{5,12,14}$. It is possible that same patients associate recovery with the disappearance of pain and paresthesia, and that mild residual sensory loss could be ignored by the patient and could explain the great benefice of surgery even in patients with severe electrodiagnosed CTS. ${ }^{12}$ Mendelson and Balla ${ }^{18}$ describing a small series, showed a tendency for patients with more severe symptoms to obtain better results from surgery.

Open carpal tunnel release remains a safe and reliable treatment of CTS ${ }^{15}$ and the relief of pain was often dramatic ${ }^{17}$. Nerve conduction improves with surgical treatment and correlates to an improvement in symptoms ${ }^{18}$. Patients with post-operative normalization of electrodiagnostic findings invariably improved clinically as well ${ }^{14}$. The results of the electrodiagnostic testing was not predictive of duration of symptoms ${ }^{13,19}$.

The present study as others indicates that the long-term postoperative results are very gratifying and we concluded the excellent surgical benefice described by patients and the absence of any predictive factors based on CTS severity, age or duration of symptomatology for outcome.

\section{REFERENCES}

1. Dawson DM, Hallett M, Wilbourn AJ. Entrapment neuropathies. 3.Ed., Philadelphia: Lippincott-Raven; 1999.

2. Stewart JD. Focal peripheral neuropathies. 3.Ed., Philadelphia: Lippincott Willians \& Wilkins; 2000.

3. de Krom MC, Knipschild PG, Kester AD, Thijs CT, Boekkooi PF, Spaans F. Carpal tunnel syndrome: prevalence in the general population. J Clin Epidemiol 1992;45:373-376.

4. Atroshi I, Gummesson C, Johnsson R, Ornstein E, Ranstam J, Rosen I. Prevalence of carpal tunnel syndrome in a general population. JAMA 1999;282:153-158

5. Nancollas MP, Peimer CA, Wheeler DR, Sherwin FS. Long-term results of carpal tunnel release. J Hand Surg (Br) 1995;20:470-474. 
6. Quality Standards Subcommittee of the American Academy of Neurology. Practice parameter for carpal tunnel syndrome (summary statement). Neurology 1993;43:2406-2409.

7. Stevens JC. American Association of Electrodiagnostic Medicine minimonograph \#26: the electrodiagnosis of carpal tunnel syndrome. Muscle Nerve 1997;20:1477-1486.

8. Andary MT, Werner RA. Electrodiagnosis in clinical decision making: carpal tunnel syndrome. 1997 AAEM Course B: Using electrodiagnosis in clinical decision making. AAEM 20th Annual Continuing Education Courses 1997, San Diego.

9. Kouyoumdjian JA. Síndrome do túnel do carpo: correlação da comparação de latência sensitiva mediano-radial com condução nervosa rotina em 1059 mãos (668 casos). Arq Neuropsiquiatr 1999;57:208-215.

10. Jablecki CK, Andary MT, So YT, Wilkins DE, Willians FH. Literature review of the usefulness of nerve conduction studies and electromyography for the evaluation of patients with carpal tunnel syndrome. Muscle Nerve 1993;16:1392-1414.

11. Johnson EW, Sipski M, Lammertse T. Median and radial sensory latencies to digit I: normal values and usefulness in carpal tunnel syndrome. Arch Phys Med Rehabil 1987;68:140-141.
12. Cseuz KA, Thomas JE, Lambert EH, Love JG, Lipscomb PR. Long-term results of operation for carpal tunnel syndrome. Mayo Clin Proc 1966;41:232-241.

13. DeStefano F, Nordstrom DL, Vierkant RA. Long-term symptom outcomes of carpal tunnel syndrome and its treatment. J Hand Surg 1997;22:200-210.

14. Haupt WF, Wintzer G, Schop A, Löttgen J, Pawlik G. Long-term results of carpal tunnel decompression: assessment of 60 cases. J Hand Surg (Br) 1993;18:471-474.

15. Thurston A, Lam N. Results of open carpal tunnel release: a comprehensive, retrospective study of 188 hands. Aust N Z Surg 1997;67:283-288.

16. Harris CM, Tanner E, Goldstein MN, Pettee DS. The surgical treatment of the carpal tunnel syndrome correlated with preoperative nerve conduction studies. J Bone Joint Surg Am 1979;61:A93-98.

17. Hybbinette $\mathrm{C}-\mathrm{H}$, Mannerfelt $\mathrm{L}$. The carpal tunnel syndrome. A retrospective study of 400 operated patients. Acta Orthop Scand 1975;46:610-620.

18. Mendelson B, Balla J. Results of surgical treatment of the carpal tunnel syndrome. Proc Aust Assoc Neurol 1973;9:129-132.

19. Kouyoumdjian JA. Carpal tunnel syndrome: age, nerve conduction severity and duration of symptomatology. Arq Neuropsiquiatr 1999;57:382-386. 